\title{
Studies on stability of emulsions containing carotenoids
}

\author{
Joanna Igielska-Kalwat ${ }^{\bowtie}$ \\ Faculty of Cosmetology and Educational Sciences, College of Health and Beauty Education, Poznań, Poland
}

Emulsions are commonly used to improve aesthetics but they may also be applied to deliver active ingredients. Recently, a group of pigments known as carotenoids has been added to emulsions as an active compound mainly due to their antioxidant properties. The stability of these formulations is a critical parameter for both, pharmaceutical and cosmetics industry. Therefore, in this study two analytical methods, multiple light scattering and laser diffraction, were tested to determine the stability of various emulsions containing carotenoids ( $\beta$-carotene, lycopene, astaxanthin). Even small changes in stability of emulsions were determined very early. The results of both methods proved that the type of carotenoid used did not influence the emulsions' stability. The stability of emulsions depends mainly on the preparation methods and on the type of emulsifier applied.

Key words: carotenoids, particle size, semisolid formulations, stability studies

Received: 13 March, 2018; revised: 11 May, 2018; accepted: 06 June, 2018; available on-line: 29 August, 2018

e-mail: joanna.igielska@wp.pl

Abbreviations: LD, laser diffraction; MLS, multiple light scattering; o/w, oil-in-water; w/o, water-in-oil

\section{INTRODUCTION}

In recent years, thanks to technological advances, a rapid development of various cosmetics and pharmaceutical formulations has been observed. Stability tests of these preparations are one of the most critical parameters for the pharmaceutical and cosmetic industries. These tests are performed in order to confirm the appropriate physicochemical standards of the obtained products (Regulation (EC) No 1223/2009 of the European Parliament and of the Council of 30 November 2009 on cosmetics products). In simple terms, emulsion stability is the ability to keep particle size unchanged with time and during storage (Curt, 1994; Tadros, 2008; Lindgren et al., 1996). The destabilization processes of the emulsions are the results of various phenomena, such as creaming, sedimentation, flocculation, coalescence, phase inversion or Ostwald ripening, that can occur separately or simultaneously (Curt, 1994; Tadros, 2008). Stability test carried out by a classical method involves observation of the sample under different conditions and is very time consuming due to the diversity and complexity of the recently obtained cosmetics and pharmaceutical products. The main parameter which is used to predict shelf life of a given formulation is temperature dependent. The effects on product shelf life by storage and shipping conditions, such as high and low temperatures, exposure to sunlight and humidity, need to be taken into account. Therefore, the formulations are stored under various conditions and are periodically analyzed for 3 to 6 months. The general conditions used to evaluate the emulsions' stability are given in the Cosmetic Regulation in Competitive Environment (Estrin \& Akerson, 2000), in a Technical Brief (Emulsion stability and testing, Technical Brief, Particle Sciences Drug Development, Manufacturing \& Delivery Services, 2011) and in the monograph published by the International Federation of Societies of Cosmetics Chemists (The Fundamentals of Stability Testing (IFSCC Monograph No. 2). International Federation of Societies of Cosmetic Chemists, Micelle Press, Cranford, NJ, 1992). Identification time of the instability phenomena can be dramatically shortened by using optical methods, such as multiple light scattering (MLS). Even small changes in the stability of emulsion can be determined very early and promptly. In addition, this method does not involve the dilution of the emulsion and therefore the emulsion structure is not disrupted (Szaferski \& Mitkowski, 2016).

Commonly known emulsions, such as oil-in-water $(\mathrm{o} / \mathrm{w})$ and water-in-oil (w/o) types, are not only used to improve aesthetics and ease of application but they may also be used to deliver active ingredients and improve their distribution and permeation. Carotenoids are an important group of organic pigments which has been recently added as active ingredients to cosmetic emulsions. They are divided into two classes, such as carotenes, which are purely hydrocarbons and contain no oxygen $(\alpha, \beta, \gamma$-carotenes, lycopene), and xantophylls, which contain oxygen (lutein, zeaxanthin, astaxanthin) (Morganti et al., 2009; Scarmo et al., 2010; Igielska-Kalwat et al., 2012; Igielska-Kalwat et al., 2013a; Igielska-Kalwat et al., 2013b). Carotenoids have found application in the cosmetics industry due to their antioxidant properties (Yamashita, 2002; Anuncuato \& da Rocha Filho, 2012). They are able to inhibit free radical formation and stimulate fibroblasts to produce collagen and elastin; therefore the skin texture, elasticity and firmness could be improved (Cabrić \& Pokrywka, 2010).

Recently, Palombo and coworkers (Palombo et al., 2007) have studied the efficacy of lutein and zeaxanthin on human skin. These xanthophylls were administrated orally, topically or in combination. According to their results, a significant enhancement of elasticity of skin was observed. Additionally, the combined oral and topical administration of both carotenoids provided the highest degree of antioxidant protection. It has been observed that carotenoids are more frequently applied in cosmetics products. They could be mostly found in anti-aging, anti-acne, and softening creams, as well as in products that protect against photo-aging effects (Beutner et al., 2001; Seki et al., 2001; Arakane, 2008; Gunasekera et al., 2007; Tominaga et al. 2012; Lee \& Chen, 2002; Gärtner et al., 1997; Hallmann \& Rembiałkowska, 2007; Toor et al., 2006). 
Function of the cosmetic's packaging is primarily protection of its contents. That is why it is so important to be aware of the choice of the packaging material's properties that is in direct contact with the product. Carotenoids show strong instability under the influence of oxygen, sun and high temperature. In this study, emulsions were stored in "air-less" type containers which are designed to provide the highest comfort of use. In these bottles, the cream is pushed out by the floating bottom. The contents of the packaging are protected from oxidation as efficiently as possible. The hygienic form of storing the cosmetic in the air-less packaging allows the use of milder preservatives and protects the carotenoids contained therein. In addition, the packaging was made of amber glass, which is characterized by higher thermal and chemical resistance. Addition of boron oxide $\mathrm{B}_{2} \mathrm{O}_{3}$ causes a reduction in the coefficient of thermal expansion (reduced sensitivity of the glass to changes in temperature).

Therefore, the aim of this study was to determine the stability of various emulsions containing carotenoids ( $\beta$-carotene, lycopene, astaxanthin) by using analytical methods: laser diffraction (LD) and multiple light scattering. Appropriate particle size and stability of cosmetic formulation guarantees high quality products (Lee \& Chen, 2002; Gärtner et al., 1997; Hallmann et al., 2007; Toor et al., 2006; Johnson et al., 1997; Lemarchand et al., 2003a). That is why results obtained here may contribute to a better understanding of the stability aspects of semisolid formulations containing active compounds.

\section{MATERIALS AND METHODS}

Procedures. Composition of formulations is presented in Table 1.

The study was conducted on different formulations containing carotenoids prepared in the laboratory.

Preparation of $\mathbf{o} / \mathbf{w}$ emulsion $\mathbf{A}$. The oil phase ingredients were placed in a $25 \mathrm{~mL}$ beaker (sunflower oil, glycerol monostearate and cetyl alcohol), and then heated to $70^{\circ} \mathrm{C}$ by using a plate heater with heating control and magnetic stirrer. IKA T 50 basic Ultra-Turrax homogenizer with rotational speed of $4000 \mathrm{rpm}$ (Mitkowski \& Szaferski, 2016) was used for $25 \mathrm{~min}$. At the same time, water was placed in a $50 \mathrm{~mL}$ beaker and heated to a temperature of $70^{\circ} \mathrm{C}$. When all oil phase ingredients were melted, they were slowly added to the water. Next, the mixture was vigorously stirred and cooled down. Afterwards, the emulsion was divided into three portions. To each portion different carotenoid - astaxanthin, $\beta$-carotene or lycopene, was added.

Preparation of $\mathbf{o} / \mathbf{w}$ emulsion B. In a $50 \mathrm{~mL}$ beaker, Creagel EZ7 was stirred with Alphaflow 20 until the mixture became homogenous. Afterwards, water was slowly added while mixing both phases by using a plate heater with heating control and magnetic stirrer, at room temperature with rotational speed of $2500 \mathrm{rpm}$ for 10 minutes (Mitkowski \& Szaferski, 2016). Next, the emulsion was divided into three portions. To each portion different carotenoid - astaxanthin, $\beta$-carotene or lycopene, was added.

Preparation of w/o emulsion. The oil phase (lanolin, sunflower oil, beeswax and cetyl alcohol) was placed in $50 \mathrm{~mL}$ beaker and heated to $70^{\circ} \mathrm{C}$ until all ingredients were melted. At the same time, water was also heated to $70^{\circ} \mathrm{C}$. While the melted oil phase ingredients were mixed by using plate heater with heating control and magnetic stirrer, the water was slowly added. IKA T 50 basic Ultra-Turrax homogenizer with rotational speed of 4000 rpm (Mitkowski \& Szaferski, 2016) was used for 25 min. The obtained mixture was allowed to cool down to room temperature. Afterwards, the emulsion was divided into three portions. To each portion different carotenoid - astaxanthin, $\beta$-carotene or lycopene, was added.

Stability studies. Stability test by Multiple Light Scattering. Stability measurements were performed immediately after preparation of the emulsions and at different times for 100 days afterwards, by using Turbiscan Lab Expert (Formulaction, France). The stability was measured under two different conditions: at room temperature $\left(25^{\circ} \mathrm{C}\right)$ and at an elevated temperature $\left(45^{\circ} \mathrm{C}\right)$, by multiple light scattering. Between measurements, the samples were stored in daylight and in darkness, at $25^{\circ} \mathrm{C}$ and at $45^{\circ} \mathrm{C}$. The obtained results were evaluated as backscattering data as a function of sample height. Before, analysis samples were placed in cylindrical glass tubes avoiding formation of bubbles.

Particle size distribution analysis by Laser Diffraction. The particle size distributions of formulations containing carotenoids were analyzed by Mastersizer 2000 (Malvern, UK) equipped with a Hydro dispersion unit. The pump speed was set at $2000 \mathrm{rpm}$.

The collected data were calculated by Frauhofer and Mie theories to obtain the particle size distribution of the analyzed samples (User manual of particle size analyzer Mastersizer 2000). The measurements were carried out at room temperature in distilled water. They were performed in triplicate and then the average value was determined. The refractive indexes of emulsions are shown in Table 2.

The results are shown as the percentages of $d(0.1), d$ (0.5) and $\mathrm{d}(0.9)$ :

- $\mathrm{d}(0.1)[\mu \mathrm{m}]-10 \%$ of the particle distribution is below this value,

- $\mathrm{d}(0.5)[\mu \mathrm{m}]-$ median of particle distribution

- d (0.9) [ $\mu \mathrm{m}]-90 \%$ of the particle distribution is below this value.

Droplet size was reported as the volume surface mean diameter, $\mathrm{D}_{[3,2]}$, and volume mean diameter, $\mathrm{D}_{[4,3]}$. $\mathrm{D}_{[3,2]}$ gives information about the mean diameter where the most of the particles fall, and $\mathrm{D}_{[4,3]}$ is sensitive to changes in particle size involving a destabilization process (Relikn \& Sourdet, 2005). Measurements were done according to the U.S. Pharmacopeia guidance "Light diffraction measurement of particle size" (USP29-NF24).

\section{RESULTS AND DISCUSSION}

It is known that carotenoids undergo photo and thermal degradation (Rodriguez-Amaja \& Kimura, 2004). It is thought that degradation of the active compound could also influence the stability of the entire system. Therefore, stability studies of the formulations with carotenoids were carried out in daylight and also in darkness to minimize the risk of carotenoid decomposition. Measurements were also conducted under various temperature conditions. Analyses at room temperature enable to predict the stability of the product stored in magazines, shops and at home, while measurements at $45^{\circ} \mathrm{C}$ serve as accelerated aging stability tests. These studies enable to analyze the emulsion stability under extreme storage conditions. The obtained formulations exhibited various organoleptic properties. The o/w emulsion B had a light consistency and white color, whereas w/o emulsion had a thick consistency with slightly yellow color, and $\mathrm{o} / \mathrm{w}$ emulsion $\mathrm{A}$ was thick and white. 
Table 1. Chemical composition of formulations.

\begin{tabular}{|c|c|c|c|}
\hline Sample name & Composition & Company & Quantity[\% \pm 0.01$]$ \\
\hline \multirow[t]{8}{*}{$\mathrm{O} / \mathrm{W}$ emulsion $\mathrm{A}$} & Sunflower oil & & 12.62 \\
\hline & Glycerol monostearate & Sigma-Aldrich & 3.89 \\
\hline & Cetyl alcohol & Sigma-Aldrich & 5.82 \\
\hline & Distilled water & & 77.66 \\
\hline & Carotenoids: & & \\
\hline & $\beta$-carotene & TriMen Chemicals & 0.01 \\
\hline & Astaxanthin & TriMen Chemicals & \\
\hline & Lycopene & TriMen Chemicals & \\
\hline \multirow[t]{7}{*}{$\mathrm{O} / \mathrm{W}$ emulsion $\mathrm{B}$} & Creagel EZ 7* & Creations Couleurs & 10.0 \\
\hline & Alphaflow $20^{* *}$ & Creations Couleurs & 17.00 \\
\hline & Distilled water & & 72.99 \\
\hline & Carotenoids: & TriMen Chemicals & 0.01 \\
\hline & $\beta$-carotene & TriMen Chemicals & \\
\hline & Astaxanthin & TriMen Chemicals & \\
\hline & Lycopene & & \\
\hline \multirow[t]{9}{*}{ W/O emulsion } & Lanolin & Fluka Analytical & 10.21 \\
\hline & Sunflower oil & & 39.90 \\
\hline & Beeswax & & 4.99 \\
\hline & Cetyl alcohol & Sigma- Aldrich & 4.99 \\
\hline & Distilled water & & 39.90 \\
\hline & Carotenoids: & & \\
\hline & $\beta$-carotene & TriMen Chemicals & 0.01 \\
\hline & Astaxanthin & TriMen Chemicals & \\
\hline & Lycopene & TriMen Chemicals & \\
\hline
\end{tabular}

${ }^{*}$ Creagel EZ7, polyacylamide, hydrogenated polydecene, laureth-7; **Alphaflow 20, hydrogenated polydecene

Emulsions $\mathrm{A}$ and $\mathrm{B}$ are both oil-in-water emulsions. However, they differ in the temperature of preparation, emulsifiers and application used. For this reason they were used in experiments presented here. Emulsion A is prepared at a temperature of $70^{\circ} \mathrm{C}$. This temperature is required for melting of the emulsion's individual components and obtaining a suitable consistency. However, emulsion B was cold-processed. Its preparation does not require the use of high temperature, making the unstable carotenoids more durable. Type A emulsion contains emulsifiers in its composition, such as glycerol monostearate and cetyl alcohol, while type $\mathrm{B}$ has been prepared with the use of coemulsifier, maintaining the lowest possible interfacial tension which is characterized by the highest stability. O/w-type emulsions are most often used by manufacturers for the production of moisturizing creams because they penetrate the skin more quickly and are characterized by a less oily and lighter consistency. Cold-processed emulsion B is characterized by better uniformity and high disintegration of the dispersed phase, i.e. the oil phase, and particle sizes of not more than $1 \mu \mathrm{m}$. These formulations, due to their better

Table 2. The refractive indexes of the analyzed emulsions.

\begin{tabular}{lc}
\hline Emulsion type & Refractive index \\
\hline o/w emulsion A with astaxanthin & 1.340 \\
\hline o/w emulsion B with astaxanthin & 1.386 \\
\hline w/o emulsion with astaxanthin & 1.479 \\
\hline o/w emulsion A with $\beta$-carotene & 1.345 \\
\hline o/w emulsion B with $\beta$-carotene & 1.397 \\
\hline w/o emulsion with $\beta$-carotene & 1.471 \\
\hline o/w emulsion A with lycopene & 1.342 \\
\hline o/w emulsion B with lycopene & 1.385 \\
\hline w/o emulsion with lycopene & 1.454 \\
\hline
\end{tabular}




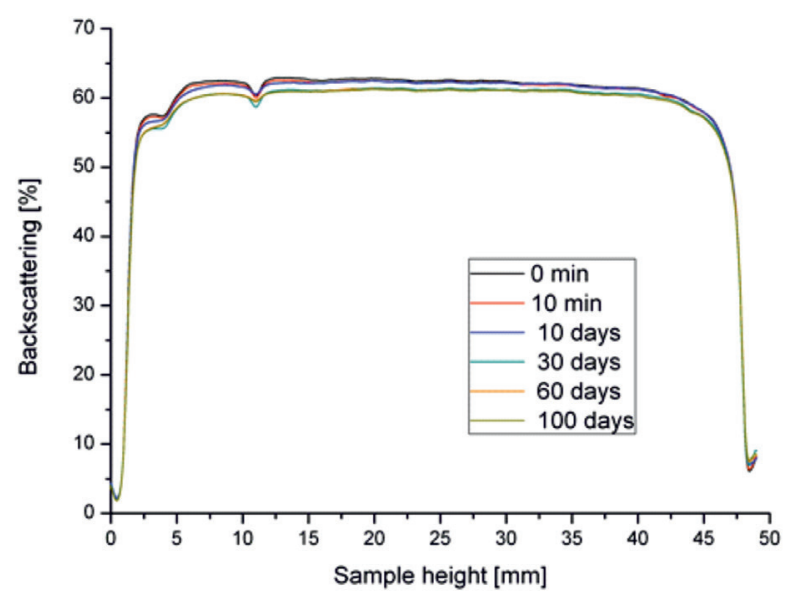

Figure 1. Backscattering profiles of o/w emulsion B with astaxanthin at room temperature.

stability and penetration of their active substances into the skin, have found application in anti-aging cosmetics. Due to lighter consistency, they are used in such products as serums, essences and lotions.

\section{Stability studies by multiple light scattering}

Measurements of the backscattered light intensity allow direct following of the emulsion stability without its dilution. The principle of this analysis is based on the variation of particle size or variation of droplet volume fraction (Celia et al., 2009a). The emission intensity most-

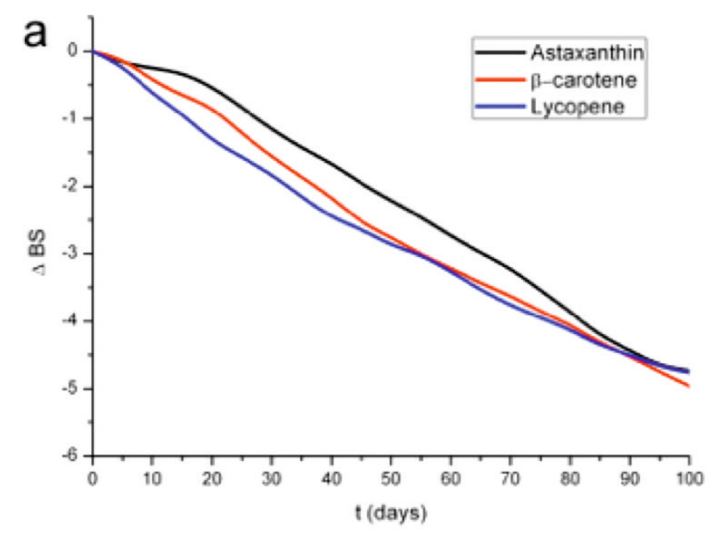

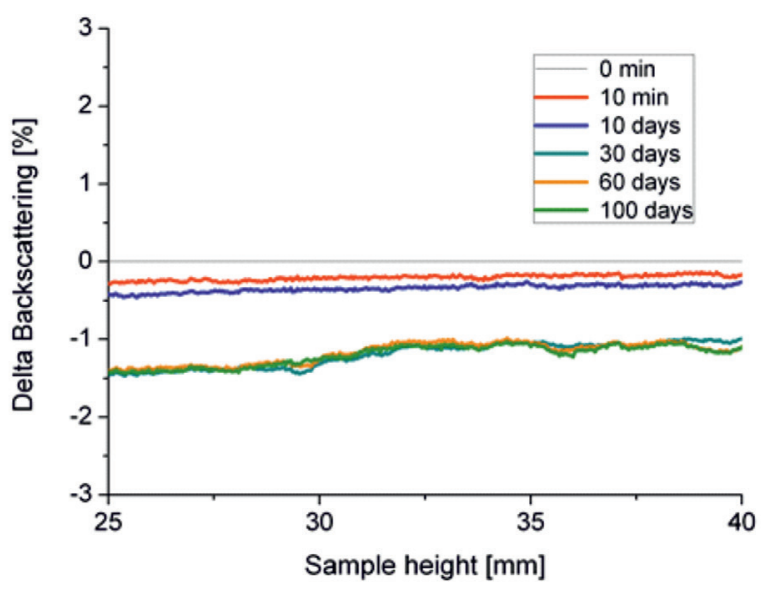

Figure 2. $\triangle B$ S profiles o/w emulsion $B$ with astaxanthin at room temperature.

ly depends on three parameters, such as particle diameter, volume fraction of the particles and the refractive index of the continuous chase and the dispersed chase (Lemarchand et al., 2003b; Vandamme \& Soetaert, 2006; Mengual et al., 1999). After analysis, two different profiles of emulsions were obtained. Only variations in the backscattering profiles of all obtained emulsions were analyzed because the transmission signal was in all cases nil (opaque samples). The backscattering fluxes were plotted as the ordinate and the height of the sample as abscissa. The light scattering fingerprints of $\mathrm{o} / \mathrm{w}$ emulsion $\mathrm{B}$ with astaxanthin is shown in Fig. 1. A regular backscattering
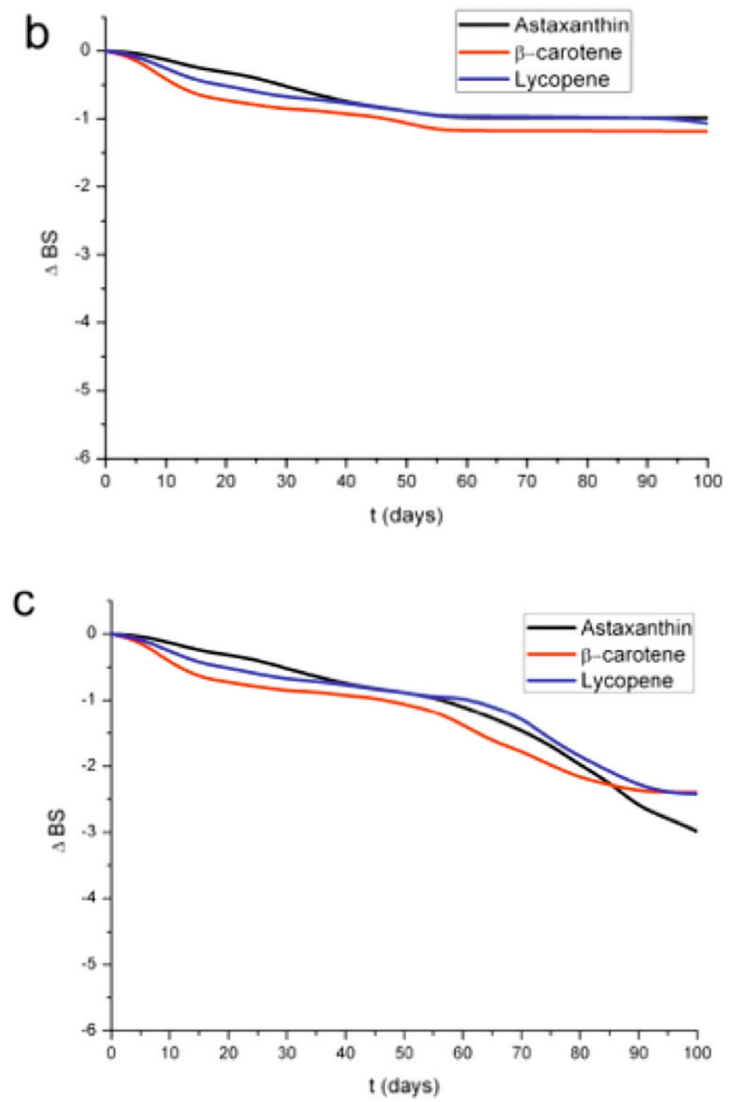

Figure 3. $\triangle B S$ profiles of o/w emulsion $A(a), o / w$ emulsion $B(b)$ and w/o emulsion (c) containing carotenoids stored in darkness at room temperature. 

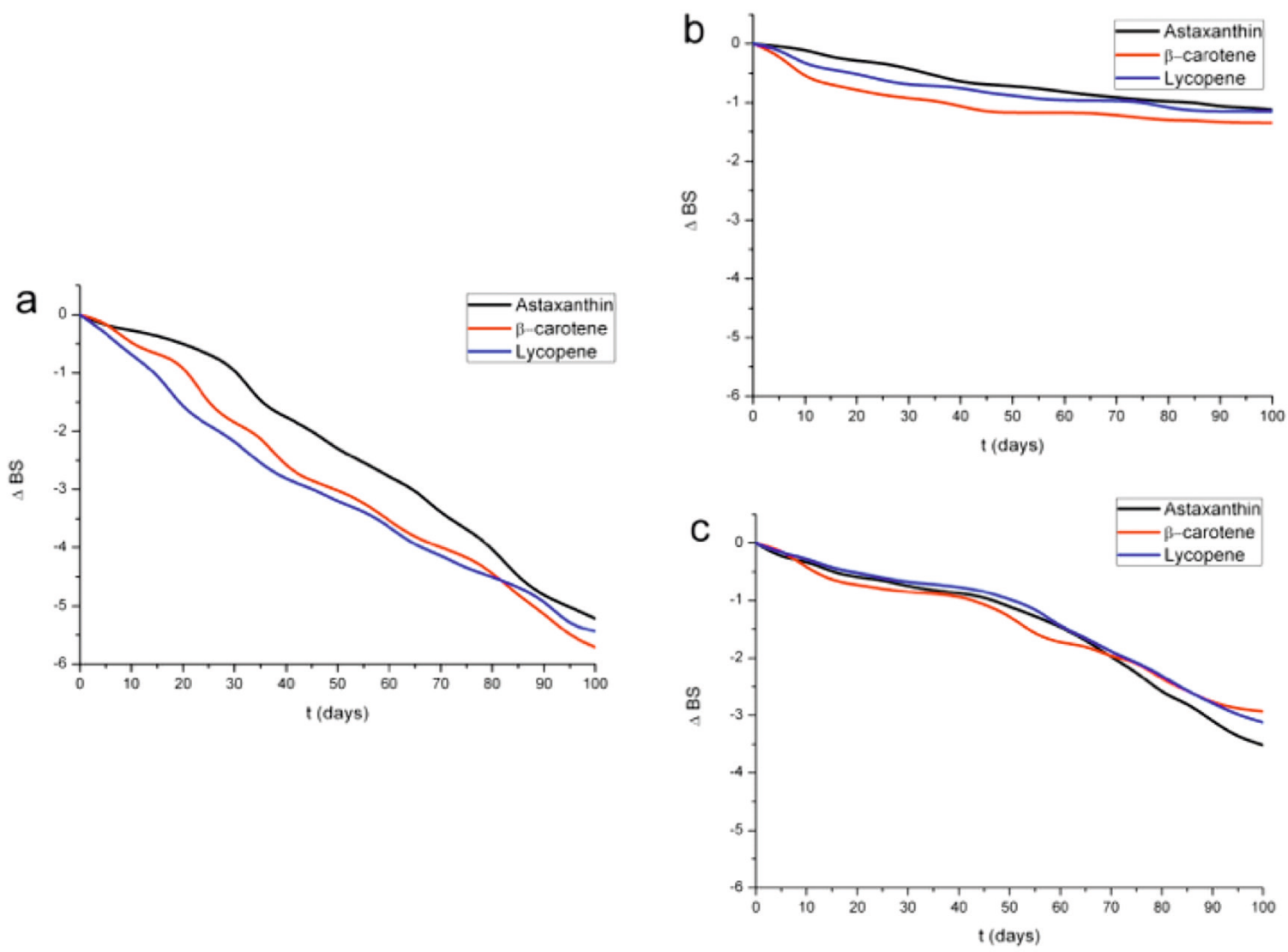

Figure 4. $\triangle B$ S profiles of o/w emulsion (Creagel) (a), o/w emulsion (b), w/o emulsion (c) stored in daylight at RT.

(BS) pattern observed along the sample height indicated the absence of sedimentation and creaming phenomena. However, the backscattering data obtained after 100 days showed a decrease in the BS intensity over the total height of the sample. These changes are related to the slight particle size variation.

In order to investigate the occurring changes and to see variations of the profiles more easily, the samples were analyzed in the reference mode. Therefore, the first profile was subtracted from all other profiles and on the ordinate the delta back scattering $(\triangle \mathrm{BS})$ was plotted. In Fig. 2 the profiles of $\mathrm{o} / \mathrm{w}$ emulsion $\mathrm{B}$ with astaxanthin are presented. The particle size variations are indicated by a variation in the backscattering level (from 0 to $-1.5 \%$ ) vs. the height of the sample tube. The first profile, at time $\mathrm{t}=0$ is at the delta line of $\mathrm{BS}=0 \%$. With time, the particles aggregate, which induces a progressive fall in delta backscattering. The intensity of backscattering light was decreasing which corresponds to the particle size increase that is known as flocculation. It is known that this phenomenon can occur when the particle size is larger than the wavelength of the incident light (Mengual et al., 1999). It should be mentioned that the BS values always change (move up or down) with particle size (Vandamme \& Soetaert, 2006). This information was applied to quantify the flocculation kinetics (Chauvierre et al., 2004; Palazolo et al., 2005). It was observed that within 100 days the maximum delta backscattering was $-1.5 \%$. This value indicates that only slight changes were observed. It should be mentioned that the formulations are treated as unstable when the variation is greater than $10 \%$, either as a positive or negative value, in the graphical scale of backscattering (Celia et al., 2009).
In Fig. 3, $\Delta \mathrm{BS}$ profiles of $\mathrm{o} / \mathrm{w}$ emulsion $\mathrm{A}(\mathrm{a}), \mathrm{o} / \mathrm{w}$ emulsion B (b) and w/o emulsion (c) containing carotenoids stored in darkness at RT are shown. The results indicate that flocculation was the main mechanism of the emulsions' destabilization. This phenomenon is observed when particles contact each other and stick together. Depending on the formulation type, variations in particle size were varied. The flocculation behavior of samples was analyzed by plotting time evolution of the delta backscattering level to enable comparison between the samples. In Fig. $3 b, \Delta \mathrm{BS}$ profiles of $\mathrm{o} / \mathrm{w}$ emulsion $\mathrm{B}$ are at the same level regardless of the carotenoids used. The particle size of droplets changed slightly $(-1 \%)$ within 40 days and then remained stable. Very similar $\Delta \mathrm{BS}$ profiles were obtained for $\mathrm{o} / \mathrm{w}$ emulsion $\mathrm{B}$ with carotenoids that were stored in daylight (Fig. 4b). The delta BS of $\mathrm{o} / \mathrm{w}$ emulsion $\mathrm{B}$ remained almost unchanged during the 100 days of storage $(-1 \%)$ indicating its high stability. On the other hand, it is shown in Fig. 3 a that after 100 days delta $\mathrm{BS}$ of $\mathrm{o} / \mathrm{w}$ emulsion $\mathrm{A}$ with carotenoids was 5 times higher than in the case of $\mathrm{o} / \mathrm{w}$ emulsion $\mathrm{B}$. The rapid flocculation in $\mathrm{o} / \mathrm{w}$ emulsion $\mathrm{A}$, regardless of the carotenoid type, took place during 100 days of storage. Very similar $\triangle \mathrm{BS}$ profiles were obtained when the same emulsion that was stored for the same period of time in daylight (Fig. 4b). Both emulsions (based on Creagel and $\mathrm{o} / \mathrm{w}$ emulsion $\mathrm{A}$ ) were oil in water type, however, they were prepared using different procedures that could influence their stability. The $\mathrm{o} / \mathrm{w}$ emulsion $\mathrm{A}$ is a typical traditional emulsion which was made by a hot process mainly due to the raw materials which are mostly in a solid form and should be melted before mixing with the aqueous phase. The other emulsion, o/w emulsion 

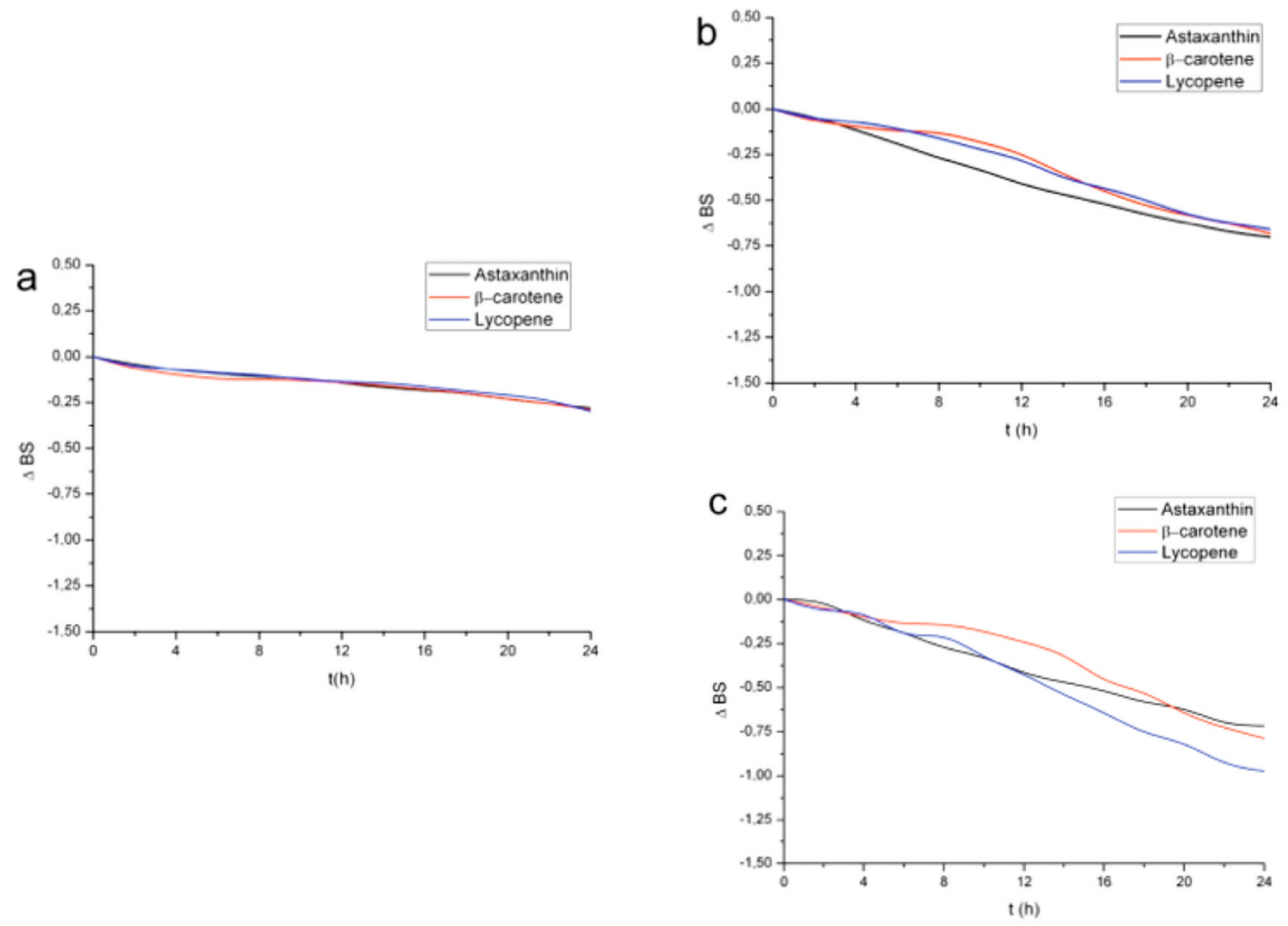

Figure 5. $\triangle B$ S profiles of o/w emulsion $A(a), o / w$ emulsion $B(b)$ and w/o emulsion (c) containing carotenoids measured at $45^{\circ} \mathrm{C}$.

B, based on Creagel, was prepared by a cold process method without melting the ingredients. The presence of Creagel EZ7, which is used as an auto-emulsifier, had an influence on maintaining the lowest interfacial tension between phases and thus it stabilized this emulsion. In comparison to w/o emulsion prepared by a hot process, the emulsion based on Creagel was also more stable. The maximum delta backscattering reached $-3 \%$ after 100 days of storage for w/o emulsion. Aggregation of the particles took place after the storage in darkness (Fig. 3c) and in daylight (Fig. 4c). Also, in this case the presence of $\beta$-carotene, astaxanthin and lycopene did not influence the formulation stability and the obtained results were very similar for each w/o emulsion with carotenoids.

Measurements conducted at a higher temperature (at $45^{\circ} \mathrm{C}$ ) showed only slight changes in delta BS for all emulsions containing carotenoids (Fig. 5). The highest particle size variation was observed in the case of w/o emulsion. It should be mentioned that in all cases the changes in delta BS were within limits. This verified that these emulsions could be stable even at a higher temperature.

\section{Stability studies by Laser Diffraction (LD)}

The particle size distribution was measured by aser diffraction. For each sample, ultrasonics were used to break up the potentially existing agglomerates and to obtain the dispersion of the primary particles. The influence of the applied ultrasound on the particle size distribution of $\mathrm{o} / \mathrm{w}$ emulsion $\mathrm{A}$ with $\beta$-carotene stored in darkness is shown in Fig. 6. The volume weighted mean diameter $\mathrm{D}_{[4,3]}$ changed from $70.14 \pm 0.44$ to $0.73 \pm 0.04 \mu \mathrm{m}$ and the volume surface mean diameter
$\mathrm{D}_{[3,2]}$ decreased from $2.07 \pm 0.01$ to $0.35 \pm 0.01 \mu \mathrm{m}$ after the application of ultrasounds $(20 \mathrm{kHz})$. This proved that the agglomerates were broken up by the action of the ultrasound. The same effect was also observed in the case of $\mathrm{o} / \mathrm{w}$ emulsion $\mathrm{A}$ with lycopene and $\mathrm{o} / \mathrm{w}$ emulsion $\mathrm{A}$ with astaxanthin, where the volume mean diameter $\mathrm{D}_{[4,3]}$ changed from $155.30 \pm 3.01$ to $0.68 \pm 0.05 \mu \mathrm{m}$ and from $51.58 \pm 5.09$ to $0.79 \pm 0.01 \mu \mathrm{m}$, respectively.

Additionally, a decrease in the volume surface mean diameter $\mathrm{D}_{[3,2]}$ from $2.06 \pm 0.02$ to $0.36 \pm 0.01 \mu \mathrm{m}$ (o/w emulsion $A$ with lycopene) and from $1.46 \pm 0.05$ to $0.36 \pm 0.01 \mu \mathrm{m}$ (o/w emulsion $\mathrm{A}$ with astaxanthin) was also observed. These results are in agreement with the data obtained for $\mathrm{o} / \mathrm{w}$ emulsion $\mathrm{A}$ with carotenoids by using multiple light scattering because the tendency of this formulation to form aggregates was proven. Additionally, thanks to the use of ultrasonication, the dispersions of the primary particles were obtained and the influence of each carotenoid on the particle size distribution could be compared. In Fig. 7, the particle size distribution of $\mathrm{o} / \mathrm{w}$ emulsion $\mathrm{A}$ containing astaxanthin, $\beta$-carotene and lycopene is presented. The results of laser diffraction measurements showed no significant changes in the droplet size distribution between the $\mathrm{o} / \mathrm{w}$ emulsion A containing different carotenoids.

It should be mentioned that the storage conditions also did not influence the particle size distribution of the $\mathrm{o} / \mathrm{w}$ emulsion $\mathrm{A}$. All the studied o/w emulsions $\mathrm{A}$ containing various carotenoids had a similar droplet size distribution regardless of whether they were kept in daylight or in darkness (Table 3). 


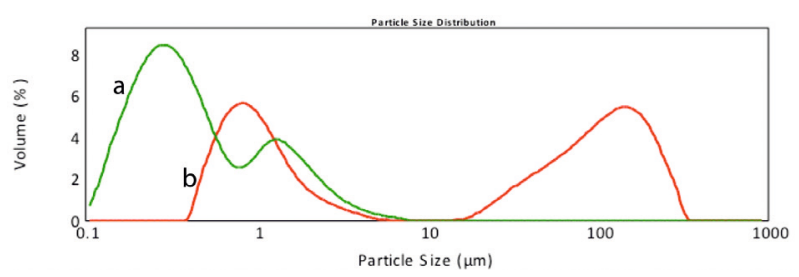

Figure 6. The influence of ultrasounds on the particle size distribution of $\mathrm{o} / \mathrm{w}$ emulsion $A$ containing $\beta$-carotene stored in darkness (b line - measurements performed without ultrasounds and a line - measurements performed with ultrasounds, $20 \mathrm{kHz}$ ).

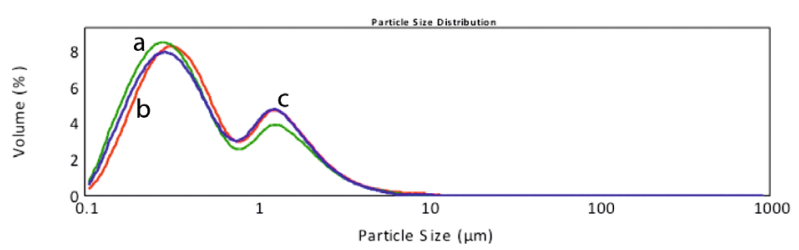

Figure 7. The particle size distribution of $\mathrm{o} / \mathrm{w}$ emulsion $\mathrm{A}$ with astaxanthin (b line), $\beta$-carotene (a line), lycopene (c line) stored in darkness.

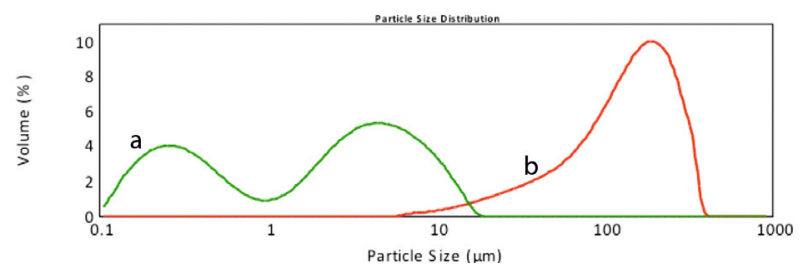

Figure 8. The influence of ultrasounds on the particle size distribution of w/o emulsion with astaxanthin stored in darkness (b line - measurements performed without ultrasounds, a line measurements performed with ultrasounds).

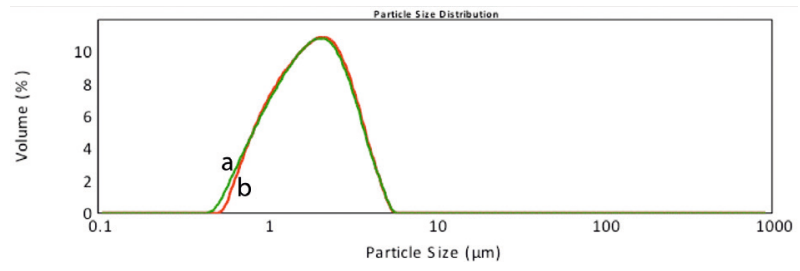

Figure 9. The influence of ultrasounds on the particle size distribution of w/o emulsion B with $\beta$-carotene stored in daylight (b line - measurements performed without ultrasounds, a line measurements performed with ultrasounds).

Table 3. Particle size distribution and volume weighted mean diameter $D_{[4,3]}$ and $D_{[3,2]}$ of o/w emulsion $A$ stored in different conditions.

\begin{tabular}{|c|c|c|c|c|c|}
\hline \multicolumn{6}{|c|}{ Stored in darkness $[\mu \mathrm{m}]$} \\
\hline $\mathrm{o} / \mathrm{w}$ emulsion $\mathrm{A}$ & $D_{[4,3]}$ & $D_{[3,2]}$ & $D_{[0.1]}$ & $\mathrm{D}_{[5.0]}$ & $\mathrm{D}_{[9.0]}$ \\
\hline$\beta$-carotene & $0.73 \pm 0.01$ & $0.34 \pm 0.01$ & $0.17 \pm 0.01$ & $0.38 \pm 0.01$ & $1.77 \pm 0.01$ \\
\hline lycopene & $0.74 \pm 0.02$ & $0.36 \pm 0.01$ & $0.18 \pm 0.02$ & $0.40 \pm 0.05$ & $1.73 \pm 0.04$ \\
\hline astaxanthin & $0.79 \pm 0.01$ & $0.35 \pm 0.01$ & $0.17 \pm 0.02$ & $0.40 \pm 0.01$ & $1.81 \pm 0.04$ \\
\hline \multicolumn{6}{|c|}{ Stored in daylight $[\mu \mathrm{m}]$} \\
\hline$\beta$-carotene & $0.73 \pm 0.05$ & $0.34 \pm 0.03$ & $0.16 \pm 0.01$ & $0.36 \pm 0.02$ & $1.75 \pm 0.11$ \\
\hline lycopene & $0.77 \pm 0.02$ & $0.36 \pm 0.01$ & $0.18 \pm 0.01$ & $0.41 \pm 0.01$ & $1.81 \pm 0.04$ \\
\hline astaxanthin & $0.77 \pm 0.02$ & $0.37 \pm 0.03$ & $0.19 \pm 0.03$ & $0.42 \pm 0.02$ & $1.71 \pm 0.03$ \\
\hline
\end{tabular}

The effect of ultrasonication was also clearly seen in the case of w/o emulsions containing carotenoids. As ultrasound was applied, agglomerates in w/o emulsion were steadily dispersed until the primary particle size was achieved. The influence of ultrasounds on the particle size distribution of w/o emulsion with astaxanthin stored in darkness is shown in Fig. 8. Before the use of ultrasounds, one broad peak between 6 and 580 $\mu \mathrm{m}$ was detected. After application of ultrasounds, this peak shifted to the smaller range of particle size. Additionally, a decrease in volume weighted mean diameter from $157.01 \pm 4.40$ to $3.72 \pm 0.19 \mu \mathrm{m}$ and change in the volume surface mean diameter $\mathrm{D}_{[3,2]}$ from 87.05 \pm 3.65 to $0.69 \pm 0.03 \mu \mathrm{m}$ was observed. As expected, due to the use of ultrasounds, the same phenomenon was also ob- served for other two w/o emulsions where the volume weighted mean diameter changed from 219.63 \pm 15.00 to $3.79 \pm 0.09 \mu \mathrm{m}$ (w/o emulsion with $\beta$-carotene) and from $236.58 \pm 8.40$ to $3.81 \pm 0.09 \mu \mathrm{m}$ (w/o emulsion with lycopene). Furthermore, after the application of ultrasounds the reduction in the volume surface mean diameter from $94.97 \pm 4.45$ to $0.61 \pm 0.06 \mu \mathrm{m}$ for $\mathrm{w} / \mathrm{O}$ emulsion with $\beta$-carotene and from $103.27 \pm 3.20$ to $0.65 \pm 0.20 \mu \mathrm{m}$ for $\mathrm{w} / \mathrm{o}$ emulsion with $\beta$-lycopene was detected. All of these results confirmed data obtained in multiple light scattering measurements, where the particles of $\mathrm{o} / \mathrm{w}$ emulsion exhibited a tendency to agglomerate. The data presented in Table 4 shows no significant difference in particle size distribution of $\mathrm{w} / \mathrm{O}$

Table 4. Particle size distribution and volume weighted mean diameter $D_{[4,3]}$ and $D_{[3,2]}$ of w/o emulsion stored in darkness.

\begin{tabular}{lccccc}
\hline & \multicolumn{5}{c}{ Stored in darkness $[\mu \mathrm{m}]$} \\
\hline W/o emulsion & $\mathrm{D}_{[4,3]}$ & $\mathrm{D}_{[3,2]}$ & $\mathrm{D}_{[0.1]}$ & $\mathrm{D}_{[0.5]}$ & $\mathrm{D}_{[0.9]}$ \\
\hdashline$\beta$-carotene & $3.91 \pm 0.26$ & $0.61 \pm 0.06$ & $0.20 \pm 0.01$ & $2.84 \pm 0.43$ & $9.74 \pm 0.32$ \\
\hline lycopene & $3.81 \pm 0.09$ & $0.65 \pm 0.02$ & $0.21 \pm 0.01$ & $3.16 \pm 0.18$ & $8.78 \pm 0.22$ \\
\hdashline astaxanthin & $3.74 \pm 0.11$ & $0.69 \pm 0.03$ & $0.22 \pm 0.01$ & $2.84 \pm 0.14$ & $9.08 \pm 0.15$ \\
\hline
\end{tabular}


emulsion containing various carotenoids stored under the same conditions.

Only in the case of $\mathrm{o} / \mathrm{w}$ emulsions $\mathrm{B}$ the changes in particle size distribution were not observed after the application of ultrasounds. In Fig. 9, the influence of ultrasounds on the particle size distribution of $\mathrm{w} / \mathrm{o}$ emulsion $\mathrm{B}$ with $\beta$-carotene stored in daylight is shown. The volume weighted mean diameter $\mathrm{D}_{[4,3]}$ and the volume surface mean diameter $\mathrm{D}_{[3,2]}$ remained constant during the measurements performed with and without ultrasonication, with an average value of $2.05 \pm 0.01 \mu \mathrm{m}$ and $1.60 \pm 0.02 \mu \mathrm{m}$, respectively. These data are in accordance with the results obtained by using multiple light scattering, where o/w emulsion B was the most stable emulsion and hardly any changes in particle size variation were observed. Moreover, it should be added that $\mathrm{o} / \mathrm{w}$ emulsion $\mathrm{B}$ containing carotenoids also displayed good stability over storage time, as the droplet size distribution did not change significantly.

\section{CONCLUSION}

The results obtained here proved that new analytical methods, such as multiple light scattering and laser diffraction, can be successfully applied to determine the stability of various formulations containing carotenoids. Here, o/w emulsion $\mathrm{B}$ that was prepared by the cold process method without melting ingredients was the most stable. The presence of auto-emulsifier could have an influence on maintaining the lowest interfacial tension between phases and thus the stability of this formulation was enhanced. The particle size distribution of $\mathrm{o} / \mathrm{w}$ emulsion $\mathrm{B}$ remained constant in measurements performed with and without ultrasonication. Additionally, no significant changes in the droplet size of emulsions were observed, regardless of carotenoids used. This proves that the addition of active compounds, such as astaxanthin, $\beta$-carotene or lycopene, did not influence the emulsion stability. Moreover, it was also found that the particle size did not change significantly under various conditions. The stability of emulsions mainly depends on the preparation methods and on the type of emulsifier applied. To conclude, we have shown that multiple light scattering (MLS) allows characterization of emulsions without dilution, and laser diffraction (LD) allows characterization of emulsions in a wide range of particle sizes $(0.01$ to $1000 \mu \mathrm{m})$, for formulation and quality control purposes. These methods have been proven to be efficient to characterize instability phenomena in emulsions in a quick and straightforward way. The proposed techniques, such as MLS (based on analyzing the temporal fluctuations in the scattered light intensity) and LD (based on analyzing the angular dependence of the scattered light intensity using Mie theory), have to be applied in order to accurately and reproducibly validate the integrity of any emulsion.

\section{Acknowledgements}

Financial support from Polish Ministry of Science and Higher Education is acknowledged.

\section{REFERENCES}

Anuncuato TP, da Rocha Filho PA (2012) Carotenoids and polyphenols in nutricosmetics, nutraceuticals, and cosmeceuticals. I Cosmet Dermatol 11: 51-54. https://doi.org/10.1111/j.1473-2165.2011.00600.x
Arakane K (2008) Superior Skin Protection via Astaxanthin, Research \& Development Division. KOSE Corporation, Tokyo

Beutner S, Bloedorn B, Frixel S, Hernández Blanco I, Hoffmann T, Martin HD, Mayer B, Noack P, Ruck C, Schmidt M, Schülke I, Sell S, Ernst H, Haremza S, Seybold G, Sies H, Stahl W, Walsh R (2001) Quantitative assessment of antioxidant properties of natural colorants and phytochemicals: carotenoids, flavonoids, phenols and indigoids. The role of $\beta$-carotene in antioxidant functions. J Sci Food Agric 81: 559-568. https://doi.org/10.1002/jsfa.849

Cabrić' M, Pokrywka L (2010) Beautiful body. Wydawnictwo Naukowe PWN, Warszawa (in Polish).

Celia C, Trapasso E, Cosco D, Paolino D, Fresta M (2009) Turbiscan lab expert analysis of the stability of ethosomes and ultradeformable liposomes containing a bilayer fluidizing agent. Coll Surf B Biointerfaces 72: 155-160. https://doi.org/10.1016/j.colsurfb.2018.04.027

Chauvierre C, Labarre D, Couvreur P, Vauthier C (2004) Long-circulating copolymers based on their emulsifying properties. Colloid Polymer Sci 282: 1097-1104. doi: 10.1021/ma034097w

Curt C (1994) Méthodes d'évaluation de la stabilité des émulsions. Principes, applications, avantages et inconvenient. Sci Aliment 14: 699-724. https://doi.org/10.1111/j.1365-2621.1996.tb12187.x

Emulsion stability and testing, Technical Brief, Particle Sciences Drug Development, Manufacturing \& Delivery Services, 2011

Estrin NF, Akerson JM (2000) Cosmetic Regulation in a Competitive Environment, pp 1-480. CRC Press, New York

Gärtner C, Stahl W, Sies, H (1997) Lycpene is more bioavailable from tomato paste than from fresh tomatoes. Am J Clin Nutr 66: 116122. doi: $10.1093 / \mathrm{ajcn} / 66.1 .116$

Gunasekera RS, Sewgobind K, Desai S, Dunn L, Black HS, McKeehan WL, Patil B (2007) Lycopene and lutein inhibit proliferation in rat prostate carcinoma cells. Nutr Cancer 58: 171-177. doi: 10.1080/01635580701328339

Hallmann E, Rembiałkowska E, Lipowski J, Marszałek K (2007) The estimation of nutritive and sensory value of the pasteurized tomato juice from organic and conventional production. I Res Appl Agric Eng 55: 105-111

Igielska-Kalwat J, Gościańska J, Nowak N (2013a) Antioxidative properties of carotenoids. Kosmetyka i Kosmetologia 96: 93-96 (in Polish)

Igielska-Kalwat J, Gościańska J, Nowak I (2013b) The use of astaxanthin in cosmetic preparations. Kosmetologia Estetyczna 2: 83-85 (in Polish)

Igielska-Kalwat J, Wawrzyńczak W, Nowak I (2012) Carotenoids and their use in the cosmetics industry on the example of $\beta$-carotene. Chemike 2: 140-144 (in Polish)

Johnson EJ, Qin J, Krinsky NI, Russell RM (1997) Ingestion by men of a combined dose of beta-carotene and lycopene does not affect the absorption of beta-carotene but improves that of lycopene. $J$ Nutr 127: 1833-1837. doi: 10.1093/jn/127.9.1833

Lee MT, Chen B.H (2002) Stability of lycopene during heating and illumination in a model system. Food Chem 78: 425-433

Lemarchand C, Couvreur P, Vauthier C, Costantini D, Gref R (2003a) Study of emulsion stabilization by graft copolymers using the optical analyzer Turbiscan. Int J Pharm 254: 77-82. https://doi. org/10.1016/S0378-5173(02)00687-7

Lemarchand C, Couvreur P, Besnard M, Costantini D, Gref R (2003b) Novel polyester-polysaccharide nanoparticle. Pharm Res 20: 1284 1292. doi: $10.1023 / \mathrm{A}: 1025017502379$

Lindgren A, Sjöström M, Wold S (1996) Quantitative-structure-effect relationship for some technical nonionic surfactants. J Am Oil Chem Soc: 73, 863-875. doi:10.3390/ijms11031020

Mengual O, Meunier G, Cayre I, Puech K, Snabre P (1999) TURBISCAN MA 2000: multiple light scattering measurement for concentrated emulsion and suspension instability analyses. Talanta 50: 445456. https://doi.org/10.1016/S0039-9140(99)00129-0

Mitkowski P, Szaferski W (2016) Production of emulsion in tank mixer with sieve bottom. ChERD 109: 618-627. doi: 10.1016/j. cej.2015.12.012

Morganti P, Martins D, Morganti G (2009) Lutein activity in the skin. SOFW - Journal - Polish edn 1: 13-18 (in Polish)

Palazolo GG, Sorgentini DA, Wagner JR (2005) Coalescence and flocculation in soy proteins in comparison with soy protein isolates. Food Hydrocoll 19: 595-604. https://doi.org/10.1016/j.foodhyd.2004.10.022

Palombo P, Fabrizi G, Ruocco V, Ruocco E, Fluhr J, Roberts R, Morganti P (2007) Beneficial long-term effects of combined oral/topical antioxidant treatment with the carotenoids lutein and zeaxanthin on human skin: a double-blind, placebo-controlled study. Skin Pharmacol Physiol 20: 199-210. doi: 10.1159/000101807

Regulation (EC) No 1223/2009 of the European Parliament and of the council of 30 November 2009 on cosmetics products. ELI: http:// data.europa.eu/eli/reg/2009/1223/oj

Relikn P, Sourdet S (2005) Factors affecting fat droplet aggregation in protein-stabilized emulsions. Food Hydrocolloid 19: 503-511. doi: 10.1016/j.foodhyd.2004.10.015

Rodriguez-Amaja DB, Kimura M (2004) Harvestplus handbook for carotenoid analysis. Harvest Plus Technical Monographs. No. 2, pp 1-58. 
International Food Policy Research Institute (IFPRI), International Center for Tropical Agriculture (CIAT) Washington

Scarmo S, Cartmel B, Lin H, Leffell DJ, Welch E, Bhosale P, Bernstein, PS, Mayne ST (2010) Significant correlations of dermal total carotenoids and dermal lycopene with their respective plasma levels in healthy adults. Arch Biochem Biophys 504: 34-39. doi: 10.1016/j. abb.2010.07.004

Seki T, Sueki H, Kohno H, Suganuma K, Yamashita E (2001) Effects of astaxanthin from Haematococcus pluvialison human skin - patch test; skin repeated application test; effect on wrinkle reduction. Fragrance J 12: 98-103

Szaferski W, Mitkowski P (2016) Aeration of liquid-liquid systems using various agitators in a mixer equipped with a membrane diffuser. Chem Eng Tech. doi: 10.1002/ceat.201500248.

Tadros TF (2008) Emulsion Science and Technology. Colloids and Interface Science Series. Wiley-VCH, Verlag, Weinheim, pp 1-344. https:// doi.org/10.1002/9783527626564.ch1
The Fundamentals of Stability Testing (1992) IFSCC Monograph No. 2. International Federation of Societies of Cosmetic Chemists. Micelle Press, Cranford, NJ. https://doi.org/10.1080/01932699308943422

Tominaga K, Hongo N, Yamashita E (2012) Cosmetic benefits of astaxanthin on humans subjects. Acta Biochim Pol 59: 43-47

Toor RK, Savage GP, Lister CE (2006). Seasonal variations in the antioxidant composition of greenhouse grown tomatoes. J Food Comp Anal 19: 1-10

User manual of particle size analyzer Mastersizer 2000

Vandamme EJ, Soetaert W (2006) Personal care products via fermentation and biocatalysis processes. In Biotechnology in Personal Care. Cosmetics Sciences and Technology Series. Taylor \& Francis, New York, pp 27-56. https://doi.org/10.1002/jctb.722

Yamashita E (2002) Cosmetic benefit of dietary supplements containing astaxanthin and tocotrienol on human skin. Food Style 21: 1121177 